\title{
A new analytical critical thrust force model for delamination analysis of laminated composites during drilling operation
}

\author{
Saheed Olalekan Ojo ${ }^{a^{*}}$, Sikiru Oluwarotimi Ismail ${ }^{b}$, Marco Paggi ${ }^{a}$, Hom Nath Dhakal ${ }^{b}$ \\ a IMT School for Advanced Studies Lucca, Piazza San Francesco 19, 55100 Lucca, Italy \\ ${ }^{\mathrm{b}}$ School of Engineering, University of Portsmouth, Portsmouth, England, PO1 3DJ, United Kingdom
}

\begin{abstract}
Fibre reinforced polymer (FRP) composite laminates are employed in many industrial applications due to their attractive mechanical and structural properties. Machining operation, such as drilling of FRP laminates, plays a significant role in the assembly of parts in aircraft and spacecraft production. Among other production bottlenecks, drilling-induced delamination remains a major defect which adversely affects the quality of assembly parts. An efficient strategy in preventing this problem is the calculation of the critical thrust force above which delamination is initiated. Therefore, in this study, a new analytical model is proposed to predict the critical thrust force for delamination. Unlike the general models in the literature which derived only mode I strain energy release rate based on the assumption of classical laminate plate theory (CLPT) combined with linear elastic fracture mechanics (LEFM) mode I considerations in the elliptic delamination zone, the proposed analytical model is derived based on first-order shear deformation theory (FSDT) and accounts for mode I and mode II strain energy release rates in the delamination zone. This strategy allows to activate mixed mode criteria for delamination initiation which is a valid assumption for laminates with layers of different orientations. The present model is partly derived for general laminates subject to distributed loading and further extended to cross-ply laminate sequence subject to a mixed load condition. The results show that the effect of shear deformation in the prediction of the critical thrust force is influential with increasing ply thickness and the effect of chisel edge on shear deformation is more profound in the distributed load regime.
\end{abstract}

Keywords: Drilling, composite laminates, delamination, linear elastic fracture mechanics, first-order shear theory, classical laminate theory.

*Corresponding author: S.O. Ojo, +393512630027, saheed.ojo@imtlucca.it 


\section{Introduction}

Fibre reinforced polymer (FRP) composite laminates possess attractive characteristics like low weight, high strength and high stiffness-to-weight ratio [1, 2]. These properties account for manufacturing of structural parts with FRP composites in the aircraft and spacecraft industries, where drilling of the structural parts is frequently encountered for manufacturing either riveted assemblies or structural repairs $[3,4]$. Due to inherent anisotropy and structural inhomogeneity in the FRP composite laminates [1], drilling operation may cause delamination in the structural parts which in turn reduces the bearing strength and stiffness of the structure $[5,6]$. This consequently impairs the load bearing capacity of the structure.

Drilling is an indispensable production process among several material removal operations such as milling, turning and boring [7]. It attracts an average of $50 \%$ of the total material removal operations $[8,9]$. Drill bit, such as twist drill, has multi-cutting parts with different designed complex geometries [7]. The geometric design of drills determines their efficiency and durability (tool life). Consequently, the total quality of the drilled holes depends on the geometry of the drill used. The geometric parts of drill include the point angle, chisel edge/angle, cutting lip [10-13], helix angle, diameter, and web [7]. These parts significantly influence drilling parameters and responses (thrust force, torque, cutting speed, feed rate, cutting force, material removal rate (MRR) and depth of cut), and also the quality of the drilled parts [14-18]. The feed rate plays a crucial role in determining the quality of drilled holes of FRP composite laminates as it determines the magnitude of the thrust force during drilling operation; thrust force mainly depends on feed rate and chisel edge [19, 62].

Calculation of the critical force during drilling of FRP composites is an important strategy to prevent delamination of the drilled parts and to improve the quality of drilled products [63]. Analysis of multilayered structures are generally developed by using the plate/shell theories for composites and by making an appropriate choice of 2D representation of the structure, type of formulation (stress-based or displacement-based) and variable description (Equivalent Single Layer Models or Layer-Wise Models) [20, 21].

The Classical Laminate Plate Theory (CLPT) approach which is a 3-parameter shell theory with classical displacement formulation and an equivalent single layer description combined with assumption of linear elastic fracture mechanics (LEFM) mode I has been employed to analyse the laminate structure during drilling operation to determine the amount of work required to initiate and cause propagation of delamination drilling-induced damage in the composite laminates [3-5, 22-27]. Classical laminate plate theory provides reasonable results for thin laminates as it ignores the effect of out-of-plane shear deformation. Consequently, CLPT underestimates deflection and overestimates buckling load of 
moderately thin or thick laminates in which shear deformation is significant [28-30]. In addition, relative displacements between layers of the composite laminates which influences delamination process [31-33] are not taken into account in CLPT since the interfaces between the layers are considered as perfectly bonded. Delamination are typically analysed by considering the interfacial interactions between different layers of the laminate which is often accomplished by cohesive zone (CZM) description of the interface between the laminates [34, 35]. The basic idea of the cohesive zone modelling of interfaces involves derivation of traction-separation law which describes the in-plane and out-of-plane tractions at the interface of the laminates together with appropriate shell theory to evaluate the onset and propagation of delamination [36-38].

To address the shortcomings of CLPT, Reissner and Mindlin [39-40] proposed the first-order shear deformation theory (FSDT) in which shear deformation is accounted for by linear variation of the inplane displacement through the thickness and introduce a shear correction factor to provide a balance between the assumed constant stress state and the actual stress state [41-42]. FSDT is a 5-parameter theory which belongs to the category of axiomatic approaches with displacement formulation and equivalent single layer description [20-21]. To reduce the number of unknowns required to perform stress analysis of plates in the traditional FSDT, Thai and Choi [43-44] proposed a modified FSDT which uses four unknowns by partitioning the transverse displacement into bending and shear components and expressing the rotational degree of freedoms as functions of the partitioned transverse displacement. Thus, reducing the unknowns and governing equations for the plates. Similar partitioning strategy has been employed for higher-order shear theory in [63].

Many analytical models in the literature focus primarily on the mechanics of the FRP composite laminates while ignoring the role of drill characteristics such as drill point geometry (drill diameter, rake angle, chisel edge angle), cutting mechanism, chip formation and cutting parameters such as the feed rate, among others [64]. Several studies on the effect of machining parameters on force and torque prediction [16, 45-49] and investigations based on numerical modelling detailed in [50-52] reveal that the total force responsible for drilling is composed of contributions from the cutting lips and the chisel edge, as illustrated in Fig. 1. Consequently, this important observation assists in reconciling the disparity between concentrated and distributed load critical thrust force models in the literature [3-5] as the total thrust force can now be adequately represented by the sum of the applied force on the cutting lips and chisel edge, respectively, as reported in [22]. In this regard, a new critical force model which accounts for the effects of the point angle was recently proposed in [53].

Exit-ply delamination is considered the most critical damage phenomenon affecting structural components under the influence of drilling [5, 23]. However, peel-up delamination which is associated 
with the geometry of the drill may occur by sliding of the plies up the flute of the drill due to unfavourable cutting conditions resulting in insufficient cutting of the fibre (see Fig. 2) [54]. It was pointed out that this type of defect constitutes $6 \%$ of the total damage of the drilling process and $27 \%$ for oval holes resulting in poor quality of drilled holes and increased manufacturing cost [55]. This phenomenon leads to the distribution of the energy release rates into different failure modes arising from different orientation of the plies around the cracked region leading to oscillatory stress and displacement around the crack tip. In this regard, analysis of critical thrust force based on mixed mode delamination is essential [54]. In addition, Silversides et al. [60] reported that delamination damage involves combination of mode I, II and III (Fig. 2), and that the inter-laminar failure energies are functions of the ratio of mode $\mathrm{I} /$ mode II loading. The onset or initiation and growth of delamination caused by bending cracks are dominated by mode I fracture toughness, while mode II and III fractures principally determined the growth and propagation of the entrenched delamination caused by transverse loading. Hence, fundamentally, mode II loading from inter-laminar fracture characterisation is required to precisely predict the delamination damage on materials.

In this paper, a new analytical model for critical thrust force during drilling operation is proposed based on modified FSDT described in [44] accounting for shear deformation during the drilling process by partitioning of the transverse displacement into bending and shear parts. A solution satisfying the elliptic crack configuration is proposed here for the transverse shear displacement based on which mode II strain energy release rate is computed. To the knowledge of the authors, this is the first analytical thrust force model derived based on FSDT. The new model is partly derived to update the modified exit-ply model proposed by Guraja et al. [5] for general laminates based on CLPT and distributed load assumptions and consequently, an extended derivation is provided for the model proposed by Ismail et al. [45] based on CLPT and mixed load assumptions for cross-ply laminates.
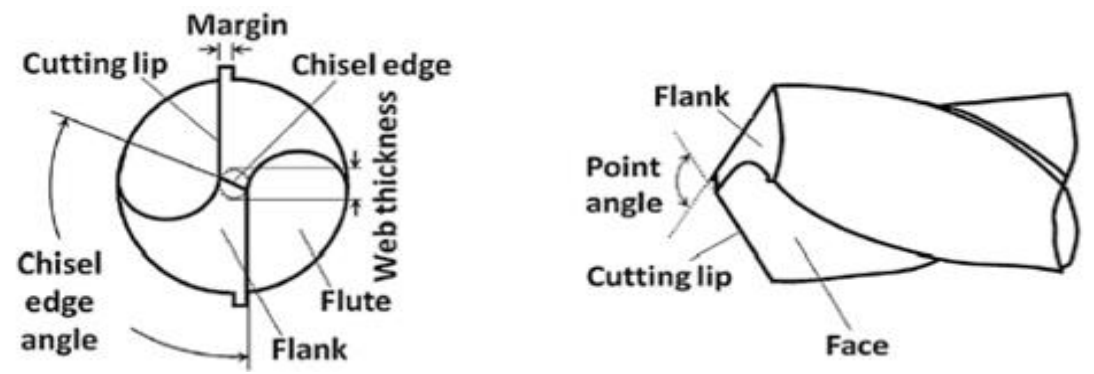

Fig. 1. A twist drill bit showing its tip and geometry [7]. 


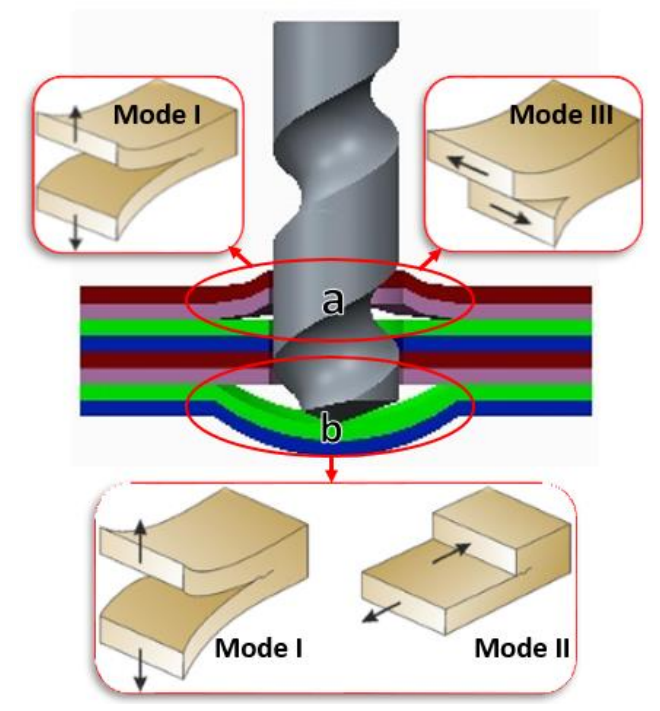

Fig. 2. Delamination phenomena depicting different modes during (a) peel-up and (b) push-out type.

\section{Model formulation for general laminates under distributed load condition.}

The kinematic relations for the first-order shear deformation theory (FSDT) is given as [44]:

$$
\begin{aligned}
& u_{1}(x, y, z)=u(x, y)+z \varphi_{x} \\
& u_{2}(x, y, z)=v(x, y)+z \varphi_{y} \\
& u_{3}(x, y, z)=w(x, y)
\end{aligned}
$$

where $u, v, w, \varphi_{x}$ and $\varphi_{y}$ are the unknown displacement functions of the midplane of the plate. Based on the work of Thai et al [43], the transverse displacement $w$ is partitioned into bending and shear components as:

$$
w=w_{b}(x, y)+w_{s}(x, y)
$$

and it is assumed in addition that the rotations take the form:

$$
\begin{aligned}
& \varphi_{x}=-\frac{\partial w_{b}}{\partial x}, \\
& \varphi_{y}=-\frac{\partial w_{b}}{\partial y} .
\end{aligned}
$$

Based on Eqs. (2-3), the displacement field is expressed as:

$$
\begin{aligned}
& u_{1}(x, y, z)=u(x, y)-z \frac{\partial w_{b}}{\partial x} \\
& u_{2}(x, y, z)=v(x, y)-z \frac{\partial w_{b}}{\partial y}
\end{aligned}
$$




$$
u_{3}(x, y, z)=w_{b}(x, y)+w_{s}(x, y)
$$

The strain field for the FSDT is defined as:

$$
\begin{aligned}
& \varepsilon_{x}=\frac{\partial u_{1}}{\partial x}=\frac{\partial u}{\partial x}-z \frac{\partial^{2} w_{b}}{\partial x^{2}} \\
& \varepsilon_{y}=\frac{\partial u_{2}}{\partial y}=\frac{\partial v}{\partial y}-z \frac{\partial^{2} w_{b}}{\partial y^{2}} \\
& \gamma_{x y}=\frac{\partial u_{1}}{\partial y}+\frac{\partial u_{2}}{\partial x}=\frac{\partial u}{\partial y}+\frac{\partial v}{\partial x}-2 z \frac{\partial^{2} w_{b}}{\partial x \partial y} \\
& \gamma_{x z}=\frac{\partial u_{1}}{\partial z}+\frac{\partial u_{3}}{\partial x}=\frac{\partial w_{s}}{\partial x} \\
& \gamma_{y z}=\frac{\partial u_{2}}{\partial z}+\frac{\partial u_{3}}{\partial y}=\frac{\partial w_{s}}{\partial y} .
\end{aligned}
$$

Considering a laminated plate with a rectangular coordinate system as shown in Fig. 3, the constitutive relation under the assumption of elastic symmetry parallel to the $x-y$ plane is given as:

$$
\left\{\begin{array}{c}
\sigma_{x} \\
\sigma_{y} \\
\sigma_{x y} \\
\sigma_{y z} \\
\sigma_{x z}
\end{array}\right\}=\left[\begin{array}{ccccc}
Q_{11} & Q_{12} & 0 & 0 & 0 \\
Q_{12} & Q_{22} & 0 & 0 & 0 \\
0 & 0 & Q_{66} & 0 & 0 \\
0 & 0 & 0 & Q_{44} & 0 \\
0 & 0 & 0 & 0 & Q_{55}
\end{array}\right]\left\{\begin{array}{c}
\varepsilon_{x} \\
\varepsilon_{y} \\
\gamma_{x y} \\
\gamma_{y z} \\
\gamma_{x z}
\end{array}\right\},
$$

where $Q_{11}=\frac{E_{1}}{1-v_{12} v_{21}}, Q_{22}=\frac{E_{2}}{1-v_{12} v_{21}}, Q_{12}=\frac{v_{12} E_{2}}{1-v_{12} v_{21}}, Q_{66}=G_{12}, Q_{44}=G_{23}, Q_{55}=G_{13}$.

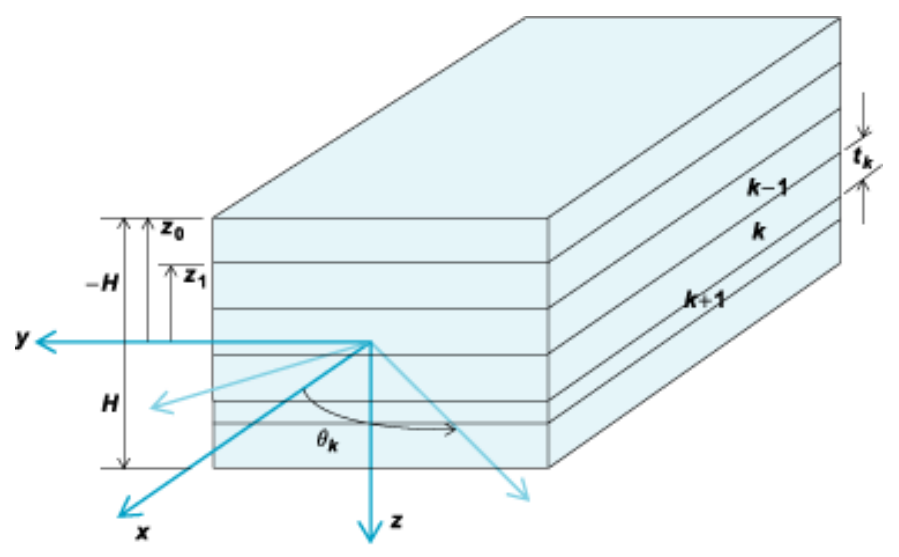

Fig. 3. Laminate geometry.

The constitutive relation for the $k$ th layer after transformation to the laminate coordinates is given as: 


$$
\left\{\begin{array}{c}
\sigma_{x} \\
\sigma_{y} \\
\sigma_{x y} \\
\sigma_{y z} \\
\sigma_{x z}
\end{array}\right\}=\left[\begin{array}{ccccc}
\bar{Q}_{11} & \bar{Q}_{12} & \bar{Q}_{16} & 0 & 0 \\
\bar{Q}_{12} & \bar{Q}_{22} & \bar{Q}_{26} & 0 & 0 \\
\bar{Q}_{16} & \bar{Q}_{26} & \bar{Q}_{66} & 0 & 0 \\
0 & 0 & 0 & \bar{Q}_{44} & \bar{Q}_{45} \\
0 & 0 & 0 & \bar{Q}_{45} & \bar{Q}_{55}
\end{array}\right]^{k}\left\{\begin{array}{c}
\varepsilon_{x} \\
\varepsilon_{y} \\
\gamma_{x y} \\
\gamma_{y z} \\
\gamma_{x z}
\end{array}\right\}^{k}
$$

where $\bar{Q}_{i j}$ are the transformed material constants whose expressions are detailed in [44].

The force and moment resultants are defined by the following equations:

$$
\begin{aligned}
& N_{x}, N_{y}, N_{x y}=\int_{-\frac{h}{2}}^{\frac{h}{2}}\left(\sigma_{x}, \sigma_{y}, \sigma_{x y}\right) \mathrm{dz}, \\
& M_{x}, M_{y}, M_{x y}=\int_{-\frac{h}{2}}^{\frac{h}{2}}\left(\sigma_{x}, \sigma_{y}, \sigma_{x y}\right) \mathrm{zdz}, \\
& Q_{x}, Q_{y}=\int_{-\frac{h}{2}}^{\frac{h}{2}}\left(\sigma_{x z}, \sigma_{y z}\right) \mathrm{dz} .
\end{aligned}
$$

Substituting Eq. (7) into (8) leads to the constitutive relation between the stress resultants and strain parameters:

$$
\begin{aligned}
& \left\{\begin{array}{c}
N_{x} \\
N_{y} \\
N_{x y} \\
M_{x} \\
M_{y} \\
M_{x y}
\end{array}\right\}=\left[\begin{array}{llllll}
A_{11} & A_{12} & A_{16} & B_{11} & B_{12} & B_{16} \\
A_{12} & A_{22} & A_{26} & B_{12} & B_{22} & B_{26} \\
A_{16} & A_{26} & A_{66} & B_{16} & B_{26} & B_{66} \\
B_{11} & B_{12} & B_{16} & D_{11} & D_{12} & D_{16} \\
B_{12} & B_{22} & B_{26} & D_{12} & D_{22} & D_{26} \\
B_{16} & B_{26} & B_{66} & D_{16} & D_{26} & D_{66}
\end{array}\right]\left\{\begin{array}{c}
\frac{\partial u}{\partial x} \\
\frac{\partial v}{\partial y} \\
\frac{\partial u}{\partial y}+\frac{\partial v}{\partial x} \\
-\frac{\partial^{2} w_{b}}{\partial x^{2}} \\
-\frac{\partial^{2} w_{b}}{\partial y^{2}} \\
-2 \frac{\partial^{2} w_{b}}{\partial x \partial y}
\end{array}\right\}, \\
& \left\{\begin{array}{l}
Q_{y} \\
Q_{x}
\end{array}\right\}=\kappa\left[\begin{array}{ll}
A_{44} & A_{45} \\
A_{45} & A_{55}
\end{array}\right]\left\{\begin{array}{l}
\frac{\partial w_{s}}{\partial y} \\
\frac{\partial w_{s}}{\partial x}
\end{array}\right\},
\end{aligned}
$$

where $\kappa$ is the shear correction factor which can be set equal to $5 / 6$ for a homogeneous plate. See [56] for the derivation of shear correction factors for arbitrary plates. The constitutive terms in Eq. (9) can be computed as:

$$
A_{i j}, B_{i j}, D_{i j}=\int_{-\frac{h}{2}}^{\frac{h}{2}} \bar{Q}_{i j}\left(1, z, z^{2}\right) \mathrm{d} z . \quad i=1,2,4,5,6
$$

The equilibrium equations are obtained based on Hamilton's principle and are given as [44]: 


$$
\begin{aligned}
& \frac{\partial N_{x}}{\partial x}+\frac{\partial N_{x y}}{\partial y}=0, \\
& \frac{\partial N_{x y}}{\partial x}+\frac{\partial N_{y}}{\partial y}=0, \\
& \frac{\partial^{2} M_{x}}{\partial x^{2}}+2 \frac{\partial^{2} M_{x y}}{\partial x \partial y}+\frac{\partial^{2} M_{y}}{\partial y^{2}}+q=0, \\
& \frac{\partial Q_{x}}{\partial x}+\frac{\partial Q_{y}}{\partial y}+q=0,
\end{aligned}
$$

where $q$ is the uniformly distributed load from drilling operation and it is related to the thrust force $P$ exerted by the drilling machine [4]:

$q=\frac{\eta P}{\pi a^{2}}, \quad \eta=\frac{a}{b}$.

where $a$ and $b$ are the half-lengths of the elliptic delamination zone as depicted in Fig. 4 and $\eta$ is the ellipcity ratio. It assumed here, according to [4], that infinitesimal propagation of delamination in the composite laminate proceeds in a self-similar fashion, i.e, $a / b=\mathrm{d} a / \mathrm{d} b=$ constant.

Substituting Eq. (9) into (11) gives:

$$
\left[\begin{array}{cccc}
H_{11} & H_{12} & H_{13} & 0 \\
H_{12} & H_{22} & H_{23} & 0 \\
H_{13} & H_{23} & H_{33} & 0 \\
0 & 0 & 0 & H_{44}
\end{array}\right]\left\{\begin{array}{c}
u \\
v \\
w_{b} \\
w_{s}
\end{array}\right\}=\left\{\begin{array}{l}
0 \\
0 \\
q \\
q
\end{array}\right\}
$$

where

$$
\begin{aligned}
& H_{11}=A_{11} \frac{\partial^{2}}{\partial x^{2}}+2 A_{16} \frac{\partial^{2}}{\partial x \partial y}+A_{66} \frac{\partial^{2}}{\partial y^{2}}, H_{12}=A_{16} \frac{\partial^{2}}{\partial x^{2}}+\left(A_{12}+A_{66}\right) \frac{\partial^{2}}{\partial x \partial y}+A_{26} \frac{\partial^{2}}{\partial y^{2}}, \\
& H_{13}=-B_{11} \frac{\partial^{3}}{\partial x^{3}}-3 B_{16} \frac{\partial^{3}}{\partial x^{2} \partial y}-\left(B_{12}+2 B_{66}\right) \frac{\partial^{3}}{\partial x \partial y^{2}}-B_{26} \frac{\partial^{3}}{\partial y^{3}}, \\
& H_{22}=A_{66} \frac{\partial^{2}}{\partial x^{2}}+2 A_{26} \frac{\partial^{2}}{\partial x \partial y}+A_{22} \frac{\partial^{2}}{\partial y^{2}}, \\
& H_{23}=-B_{16} \frac{\partial^{3}}{\partial x^{3}}-\left(B_{12}+2 B_{66}\right) \frac{\partial^{3}}{\partial x^{2} \partial y}-3 B_{26} \frac{\partial^{3}}{\partial x \partial y^{2}}-B_{22} \frac{\partial^{3}}{\partial y^{3}}, \\
& H_{33}=D_{16} \frac{\partial^{4}}{\partial x^{4}}+4 D_{16} \frac{\partial^{4}}{\partial x^{3} \partial y}+2\left(D_{12}+2 D_{66}\right) \frac{\partial^{4}}{\partial x^{2} \partial y^{2}}+4 D_{26} \frac{\partial^{4}}{\partial x \partial y^{3}}+D_{22} \frac{\partial^{4}}{\partial y^{4}}, \\
& H_{44}=A_{55} \frac{\partial^{2}}{\partial x^{2}}+2 A_{45} \frac{\partial^{2}}{\partial x \partial y}+A_{44} \frac{\partial^{2}}{\partial y^{2}} .
\end{aligned}
$$




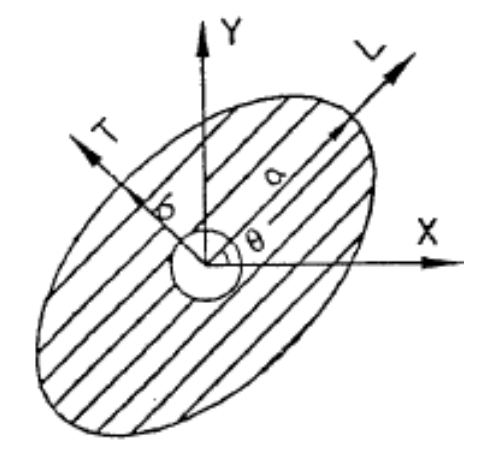

Fig. 4 Elliptic delamination area [4].

According to several studies [4-5], the boundary condition of the delamination zone is close to being clamped during drilling of the composite laminate. In line with this assumption, a clamped boundary condition is considered, and, mathematically represented as:

$$
u=v=w_{b}=w_{s}=\frac{\partial w_{b}}{\partial x}=\frac{\partial w_{b}}{\partial y}=0, \quad \text { at } \frac{x^{2}}{a^{2}}+\frac{y^{2}}{b^{2}}-1=0 .
$$

In line with the work of Zhang et al [4], the solutions for $u, v$ and $w_{b}$ displacements are taken as:

$$
\begin{aligned}
& u=\left(u_{1} \frac{x}{a}+u_{2} \frac{y}{b}\right)\left(1-\frac{x^{2}}{a^{2}}-\frac{y^{2}}{b^{2}}\right), \\
& v=\left(v_{1} \frac{x}{a}+v_{2} \frac{y}{b}\right)\left(1-\frac{x^{2}}{a^{2}}-\frac{y^{2}}{b^{2}}\right), \\
& w_{b}=w_{b 0}\left(1-\frac{x^{2}}{a^{2}}-\frac{y^{2}}{b^{2}}\right)^{2},
\end{aligned}
$$

The solution of the shear part $w_{S}$ which satisfies the boundary condition (15) is assumed to take the form:

$$
w_{s}=f(x, y)\left(1-\frac{x^{2}}{a^{2}}-\frac{y^{2}}{b^{2}}\right)
$$

Further, it is assumed that the sliding value of the energy release rate, in consistent with the opening energy release rate, takes the form:

$$
U_{s}=K_{S} P^{2} a^{2}
$$

where $K_{S}$ is a compliance term in the sliding mode, $P$ is the applied load and $a$ is the half delamination size in the longitudinal direction. Based on the assumptions (17-18), the solution of the shear part of the transverse displacement $w_{s}$ for the elliptic crack configuration (Fig. 4) is proposed here as:

$$
w_{s}=\left(\frac{x}{a^{2}} w_{s 1}+\frac{y}{b^{2}} w_{s 2}\right)\left(1-\frac{x^{2}}{a^{2}}-\frac{y^{2}}{b^{2}}\right),
$$


where $u_{1}, u_{2}, v_{1}, v_{2}, w_{b 0}, w_{s 1}$ and $w_{s 2}$ are undetermined constants. Using the procedure described in [4], the expression for these constants is obtained and we have:

$$
\begin{aligned}
& u_{1}=P C_{1} a \\
& u_{2}=P C_{2} a \\
& w_{b 0}=P C_{3} a^{2} \\
& v_{1}=P C_{4} a \\
& v_{2}=P C_{5} a
\end{aligned}
$$

where the constants $C_{i}$ are defined in [4]. Substituting Eq. (19) into Eq. (13), the solutions for $w_{s 1}$ and $w_{S 2}$ are derived as:

$$
\begin{aligned}
& w_{S 1}=\frac{P \eta a^{2}}{\pi \bar{D}_{s 1}} \\
& w_{S 2}=\frac{P \eta a^{2}}{\pi \bar{D}_{S 2}}
\end{aligned}
$$

where $\bar{D}_{s 1}=6 A_{55}+2 \eta^{2} A_{44}+4 \eta^{2} A_{45}$ and $\bar{D}_{s 2}=6 \eta^{4} A_{44}+2 \eta^{2} A_{55}+4 \eta^{2} A_{45}$.

Based on the theorem of virtual work, the total energy balance equation for the propagation of delamination during drilling operation is expressed as:

$$
\delta W=\delta U+\delta U_{d}
$$

where $\delta U_{d}=G_{c} \delta A$ is the energy absorbed due to delamination propagation and $G_{c}$ is the critical strain energy release rate under mixed mode conditions. $\delta A$ is the infinitesimal increase in the elliptic delamination area in Fig. 4, given as:

$$
\mathrm{d} A=2 \pi b \delta a .
$$

$\delta U$ is the strain energy variation which is composed of the membrane (in-plane) and the shear (outof-plane) parts, $\delta U_{b}$ and $\delta U_{s}$, respectively. Furthermore, $\delta W$ is the external virtual work of drill load. The total strain energy due to uniform load $q$ is expressed as:

$$
\begin{aligned}
& U=\frac{1}{2} \int \boldsymbol{\sigma}: \boldsymbol{\varepsilon} \mathrm{dV}, \\
& \text { where } \boldsymbol{\sigma}=\left\{\begin{array}{c}
\sigma_{x} \\
\sigma_{y} \\
\sigma_{x y} \\
\sigma_{y z} \\
\sigma_{x z}
\end{array}\right\}=\left[\begin{array}{ccccc}
\bar{Q}_{11} & \bar{Q}_{12} & \bar{Q}_{16} & 0 & 0 \\
\bar{Q}_{12} & \bar{Q}_{22} & \bar{Q}_{26} & 0 & 0 \\
\bar{Q}_{16} & \bar{Q}_{26} & \bar{Q}_{66} & 0 & 0 \\
0 & 0 & 0 & \bar{Q}_{44} & \bar{Q}_{45} \\
0 & 0 & 0 & \bar{Q}_{45} & \bar{Q}_{55}
\end{array}\right]^{k}\left\{\begin{array}{c}
\varepsilon_{x} \\
\varepsilon_{y} \\
\gamma_{x y} \\
\gamma_{y z} \\
\gamma_{x z}
\end{array}\right\}^{k}, \quad \text { and } \boldsymbol{\varepsilon}=\left\{\begin{array}{c}
\varepsilon_{x} \\
\varepsilon_{y} \\
\gamma_{x y} \\
\gamma_{y z} \\
\gamma_{x z}
\end{array}\right\}^{k}
\end{aligned}
$$


Equation (24) can be rewritten by separating the membrane and the shear components:

$$
U=U_{m}+U_{s}=\frac{1}{2} \int \boldsymbol{\sigma}_{m}: \boldsymbol{\varepsilon}_{m} \mathrm{dV}+\frac{1}{2} \int \boldsymbol{\sigma}_{s}: \boldsymbol{\varepsilon}_{s} \mathrm{dV}
$$

where $\boldsymbol{\sigma}_{m}=\left\{\begin{array}{c}\sigma_{x} \\ \sigma_{y} \\ \tau_{x y}\end{array}\right\}^{k}=\left[\begin{array}{lll}\bar{Q}_{11} & \bar{Q}_{12} & \bar{Q}_{16} \\ \bar{Q}_{12} & \bar{Q}_{22} & \bar{Q}_{26} \\ \bar{Q}_{16} & \bar{Q}_{26} & \bar{Q}_{66}\end{array}\right]^{k}, \boldsymbol{\varepsilon}_{m}=\left\{\begin{array}{c}\varepsilon_{x} \\ \varepsilon_{y} \\ \gamma_{x y}\end{array}\right\}^{k}$,

and $\boldsymbol{\sigma}_{s}=\left\{\begin{array}{l}\sigma_{y z} \\ \sigma_{x z}\end{array}\right\}^{k}=\left[\begin{array}{ll}\bar{Q}_{44} & \bar{Q}_{45} \\ \bar{Q}_{45} & \bar{Q}_{55}\end{array}\right]^{k}\left\{\begin{array}{l}\gamma_{y z} \\ \gamma_{x z}\end{array}\right\}^{k}, \boldsymbol{\varepsilon}_{s}=\left\{\begin{array}{l}\gamma_{y z} \\ \gamma_{x z}\end{array}\right\}^{k}$.

The in-plane strain energy $U_{m}$ is calculated according to the procedure detailed in [4], and is given as:

$$
U_{m}=K_{m} P^{2} a^{2}
$$

where

$$
\begin{aligned}
& K_{m}=\frac{\pi}{12}\left\{\frac{A_{11}}{\eta}\left(3 C_{1}{ }^{2}+{C_{4}}^{2}\right)+2 A_{12}\left(C_{1} C_{2}+C_{4} C_{5}\right)+A_{22} \eta\left(3 C_{2}{ }^{2}+C_{5}{ }^{2}\right)+\frac{2 A_{16}}{\eta}\left(2 \eta C_{1} C_{4}+3 C_{1} C_{5}+\right.\right. \\
& \left.C_{2} C_{4}\right)+2 A_{26}\left(3 \eta C_{2} C_{4}+2 C_{2} C_{5}+\eta C_{1} C_{5}\right)+\frac{A_{66}}{\eta}\left[\left(C_{1}+C_{2}\right)^{2}+3 \eta^{2} C_{4}{ }^{2}+3 C_{5}{ }^{2}+2 \eta C_{4} C_{5}\right]+ \\
& \frac{24 B_{11}}{\eta} C_{1} C_{3}+8 B_{12} C_{3}\left(\eta C_{1}+C_{2}\right)+24 B_{16} C_{3}\left(C_{4}+\frac{C_{5}}{\eta}\right)+24 B_{22} \eta^{2} C_{2} C_{3}+24 B_{26} \eta C_{3}\left(C_{5}+\eta C_{4}\right)+ \\
& \left.16 B_{26} C_{3}\left(\eta C_{1}+C_{2}\right)+\frac{16 C_{3}{ }^{2}}{\eta}\left(3 D_{11}+2\left(D_{12}+2 D_{66}\right) \eta^{2}+3 D_{22} \eta^{4}\right)\right\} .
\end{aligned}
$$

The expression for the shear strain energy $U_{s}$ can be written after expansion of Eq. (25) as:

$$
U_{S}=\frac{1}{2} \int_{-a}^{a} \int_{-b \sqrt{1-x^{2} / a^{2}}}^{b \sqrt{1-x^{2} / a^{2}}} \int_{-\frac{h}{2}}^{\frac{h}{2}}\left[\bar{Q}_{44} \gamma_{y z}{ }^{2}+\bar{Q}_{55} \gamma_{x z}{ }^{2}+2 \bar{Q}_{45} \gamma_{y z} \gamma_{x z}\right] \mathrm{d} V
$$

Evaluating Eq. (27) using Eqs. (5) and (19), leads to:

$$
U_{s}=K_{S} P^{2} a^{2},
$$

where $K_{S}=\frac{\eta}{12 \pi}\left[\frac{K_{S 1}}{\bar{D}_{S 1}}+\frac{K_{S 2}}{\bar{D}_{S 2}}\right]$,

and $K_{S 1}=\frac{6 A_{55}}{\bar{D}_{S 1}}+\frac{2 \eta^{2} A_{44}}{\bar{D}_{S 1}}+\frac{4 \eta^{2} A_{45}}{\bar{D}_{S 2}}, K_{S 2}=\frac{6 \eta^{2} A_{44}}{\bar{D}_{S 2}}+\frac{2 \eta^{2} A_{55}}{\bar{D}_{S 2}}+\frac{4 \eta^{2} A_{45}}{\bar{D}_{S 1}}$.

Substituting Eqs. (26) and (28) into Eq. (25) yields:

$$
U=\left(K_{m}+K_{s}\right) P^{2} a^{2} .
$$

In line with Eq. (22), the strain energy variation is:

$$
\delta U=2\left(K_{m}+K_{s}\right) P^{2} a \delta a .
$$


Considering a distributed load model, the virtual work of external load $\delta W$ may be expressed as:

$$
W=\int_{-a}^{a} \int_{-b \sqrt{1-x^{2} / a^{2}}}^{b \sqrt{1-x^{2} / a^{2}}} q\left(w_{b}+w_{s}\right) d x d y
$$

Evaluation of the integral (31) for the shear part vanishes while the bending part results in:

$$
W=\frac{P^{2} C_{3} a^{2}}{3}
$$

It is noted that Eq. (32) is the same as the one derived by Guraja et al. in [5]. Again, in line with Eq. (22), the virtual work is expressed as:

$$
\delta W=\frac{2 P^{2} C_{3}}{3} a \delta a
$$

\subsection{Critical thrust force for mixed mode delamination}

During drilling of thin composite laminates, delamination analysis is usually based on the assumption of mode I propagation which is valid especially for interfaces of unidirectional laminates in which adjacent layers have the same orientation. The delamination mode for layers of different orientations may however be more appropriately represented by a coupled loading as the stress fields near the crack tip becomes more complex. The reality of the mixed-mode assumption is even suggested when it is considered that the composite material is subjected to coupled axial force and bends during drilling operation [54]. The fracture initiation criterion which is expressed mathematically in Eq. (34) assumes a linear contribution of the fracture toughness into the mixed-mode resistance to delamination, but prevent interaction between the single modes [49]:

$$
\frac{G_{I}}{G_{I c}}+\frac{G_{I I}}{G_{I I C}}=1
$$

where $G_{I}$ and $G_{I I}$ are the energy release rates under mixed-mode conditions while $G_{I C}$ and $G_{I I c}$ are the corresponding critical values under pure modes. To obtain a fracture initiation criterion with common mixed-mode fracture toughness, i.e., $G_{c}=G_{I C}=G_{I I c}$, the B-K criterion, which is considered one of the most popular in the framework of mixed-mode fracture is considered in this work. The linear exchange between the fracture toughness of single modes under mixed-mode conditions is expressed as [57]:

$$
G_{c}=r G_{I I C}+(1-r) G_{I c}=G_{I C}+\left(G_{I I C}-G_{I c}\right) r
$$

where $r$ is the mode mixity ratio which may be chosen as:

$$
r=\left(\frac{G_{I I}}{G_{T}}\right)^{\beta}
$$


and $G_{T}=G_{I}+G_{I I}$

The parameter $\beta$ defines the shape of the failure locus in the mixed mode plane and it can be determined by matching the material response with the B-K criterion on the mixed mode diagram [57]. The mode mixity ratio will vary depending on the number of uncut plies under the drill and the cutting conditions. Replacing $G_{I}, G_{I I}$ and $G_{T}$ in Eq. (32) by $U_{m}, U_{s}$ and $U$, respectively, and simplifying, the mode mix ratio becomes:

$$
r=\left(\frac{K_{s}}{K_{m}+K_{s}}\right)^{\beta}
$$

Now, considering Eq. (22), the energy balance equation is expressed based on Eqs. (30) and (33) as:

$$
\frac{2 P_{c}^{2} C_{3}}{3} a \delta a=2\left(K_{m}+K_{S}\right) P_{c}^{2} a \delta a+2 G_{c} \pi b \delta a
$$

The critical thrust force can be expressed from Eq. (34) as:

$$
P_{c}=\sqrt{\frac{G_{c} \pi}{\eta\left(\frac{C_{3}}{3}-K_{m}-K_{s}\right)}}
$$

It is remarked here that $G_{c}$ is not constant as it depends on the mode ratio $r$ which depends on the number of uncut plies. In addition, the choice of $r$ in Eq. (37) ensures that the critical thrust force formulation using the classical laminate theory is recovered when $K_{S}$ vanishes subject to vanishing shear transverse displacement $w_{S}$.

\section{Model formulation for cross-ply under mixed load condition}

A special case of cross-ply laminate as described in [53] without thermal effects is herein considered where the extensional and bending stiffness matrices are uncoupled so that the resultant moments, according to classical Kirchhoff's assumption, neglecting the in-plane displacement, are expressed as:

$$
\left\{\begin{array}{l}
M_{x} \\
M_{y} \\
M_{x y}
\end{array}\right\}=\left[\begin{array}{ccc}
D_{11} & D_{12} & 0 \\
D_{12} & D_{22} & 0 \\
0 & 0 & D_{66}
\end{array}\right]\left\{\begin{array}{c}
k_{x} \\
k_{y} \\
k_{x y}
\end{array}\right\},
$$

where $\left\{\begin{array}{c}k_{x} \\ k_{y} \\ k_{x y}\end{array}\right\}=\left\{\begin{array}{c}-\frac{\partial^{2} w_{b}}{\partial x^{2}} \\ -\frac{\partial^{2} w_{b}}{\partial y^{2}} \\ -2 \frac{\partial^{2} w_{b}}{\partial x \partial y}\end{array}\right\}$

Since the displacement according the modified FSDT includes both the bending and the shear part, the shear force for the cross-ply laminate is expressed as: 


$$
\left\{\begin{array}{l}
Q_{y} \\
Q_{x}
\end{array}\right\}=\left[\begin{array}{cc}
A_{44} & 0 \\
0 & A_{55}
\end{array}\right]\left\{\begin{array}{l}
\frac{\partial w_{s}}{\partial y} \\
\frac{\partial w_{s}}{\partial x}
\end{array}\right\}
$$

and the equilibrium equations for the composite plate is given as:

$$
\begin{aligned}
& \frac{\partial^{2} M_{x}}{\partial x^{2}}+2 \frac{\partial^{2} M_{x y}}{\partial x \partial y}+\frac{\partial^{2} M_{y}}{\partial y^{2}}+q=0, \\
& \frac{\partial Q_{x}}{\partial x}+\frac{\partial Q_{y}}{\partial y}+q=0 .
\end{aligned}
$$

\subsection{Critical thrust force for cross-ply laminates under mixed load conditions}

To calculate the critical thrust force, the following assumptions are put forward:

1. The uncut laminate under the drill bit exhibits an orthotropic nature.

2. The delamination zone around the exit drilled hole, with clamped boundary condition, is considered elliptical.

3. Self-similar growth of the crack or inter-laminar delamination, making suitable the application of LEFM approach.

4. The chisel edge force is modelled as a concentrated (point) load, while the cutting lip force is modelled as a uniformly distributed load.

The thrust force is a component of cutting (drilling) force along the drill bit axis. In accordance with [22], the total thrust force for the uncut ply is accounted for by part contributions from the chisel edge and the cutting lips of the drill, as detailed in Fig. 5. Investigation shows in [58] that the chisel edge force has a greater contribution than the cutting lips and is hereby modelled as a concentrated (point) load $q_{c}$ while the cutting edge is modelled as a uniformly distributed load $q_{L}$. The uniformly distributed load is herein considered, because the downward thrust force spreads out over the chisel edge and it does not pass through the centre of the drill bit during the first phase of delamination and drilling operation as a point (concentrated) load. Also, the distributed load profile has a closer agreement with the experimental results [5]. Since the linear elastic regime is considered, the total thrust force can be obtained using the law of superposition as:

$$
P=P_{c}+P_{L},
$$

where $P_{c}$ and $P_{L}$ are, respectively, thrust force contributions due to concentrated and distributed loads. Let us define 2 ratios to express the relationship between $P_{C}$ and $P_{L}$ as:

$$
\alpha=\frac{P_{c}}{P_{L}}, \text { for } \geq 0 \text {. }
$$


Using the $\alpha$ parameter and considering Eq. (43), the thrust forces $P_{c}$ and $P_{L}$ can be expressed as:

$$
\begin{aligned}
& P_{c}=\left(\frac{\alpha}{1+\alpha}\right) P=\gamma P \\
& P_{L}=\left(\frac{1}{1+\alpha}\right) P=(1-\gamma) P
\end{aligned}
$$

where $\gamma=\left(\frac{\alpha}{1+\alpha}\right)$ is the chisel edge ratio for $0 \leq \gamma \leq 1$.

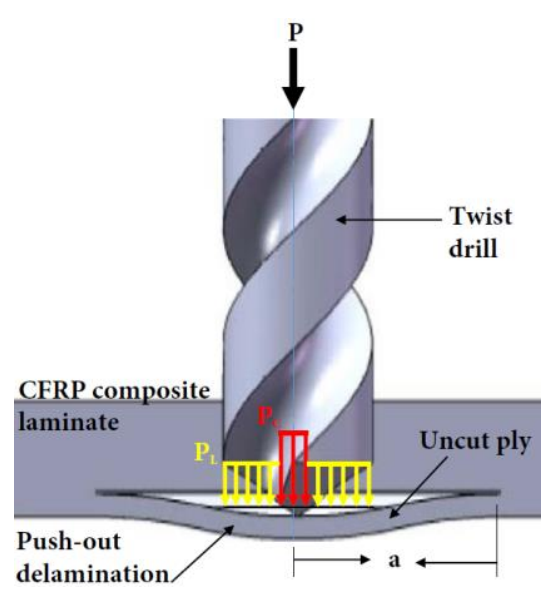

(a) Distributed loads on chisel edge and cutting lips.

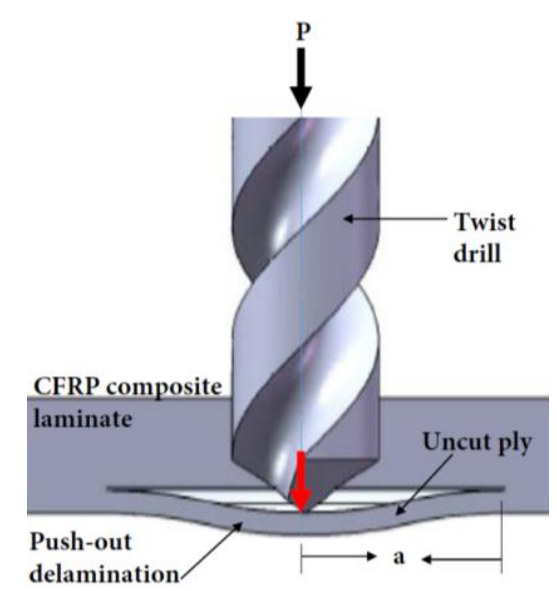

(b) Concentrated load on chisel edge

Fig. 5. Thrust force models [53].

Following the procedure described in [53], the strain energy and external work due to bending can be expressed as:

$$
\begin{aligned}
& U_{b}=\frac{P^{2} \eta a^{2}}{144 \pi D^{*}}\left(16 \gamma^{2}+(1-\gamma)^{2}\right), \\
& W_{b}=\frac{P^{2} a^{2} \eta}{72 \pi D^{*}}\left(12 \gamma^{2}+(1-\gamma)^{2}\right) .
\end{aligned}
$$

where $D^{*}=D_{11}+\frac{2}{3}\left(D_{12}+2 D_{66}\right) \eta^{2}+D_{22} \eta^{4}$.

Using the same procedure as detailed in Sec. 2 for the derivation of the shear part of the strain energy of the laminate coupled with the assumption of mixed load contributions in Eq. (43), the strain energy and external work due to shear are given as:

$$
\begin{aligned}
& U_{S}=\frac{P^{2} \eta a^{2}}{24 \pi\left(\bar{D}_{1}+\bar{D}_{2}\right)}\left(16 \gamma^{2}+(1-\gamma)^{2}\right), \\
& W_{S}=0 .
\end{aligned}
$$

where $\bar{D}_{1}=6 A_{55}+2 \eta^{2} A_{44}$ and $\bar{D}_{2}=6 A_{44} \eta^{4}+2 \eta^{2} A_{55}$. 
The total strain energy $(U)$ and the total external work $(W)$ based on Eqs. (46-47) are now expressed as:

$$
\begin{aligned}
& U=U_{b}+U_{s}=\frac{P^{2} \eta a^{2}}{\pi}\left[\frac{1}{144 D^{*}}+\frac{1}{24\left(\bar{D}_{1}+\bar{D}_{2}\right)}\right]\left(16 \gamma^{2}+(1-\gamma)^{2}\right) \\
& W=\frac{P^{2} a^{2} \eta}{72 \pi D^{*}}\left(12 \gamma^{2}+(1-\gamma)^{2}\right)
\end{aligned}
$$

With regards to Eqs. (46a) and (47a), and in line with Eq. (36), the mode ratio for delamination fracture is:

$$
r=\left(\frac{1}{24\left(\bar{D}_{1}+\bar{D}_{2}\right)} \frac{1}{\left[\frac{1}{144 D^{*}}+\frac{1}{24\left(\bar{D}_{1}+\bar{D}_{2}\right)}\right]}\right)^{\beta}
$$

Differentiating Eq. (48) in accordance with Eq. (22) and substituting gives:

$\frac{P^{2} a \eta}{36 \pi D^{*}}\left(12 \gamma^{2}+(1-\gamma)^{2}\right) \delta a=\frac{P^{2} \eta a}{\pi}\left[\frac{1}{72 D^{*}}+\frac{1}{12\left(\bar{D}_{1}+\bar{D}_{2}\right)}\right]\left(16 \gamma^{2}+(1-\gamma)^{2}\right) \delta a+2 G_{c} \pi b \delta a$

The critical thrust force from Eq. (50) can be expressed as:

$$
P_{c}=\frac{12 \pi}{\eta} \sqrt{\frac{2 G_{c}}{\mathrm{~K}}}
$$

where $K=\frac{\left(16 \gamma^{2}+2(1-\gamma)^{2}\right)}{D^{*}}-\frac{\left(96 \gamma^{2}+6(1-\gamma)^{2}\right)}{\left(\bar{D}_{1}+\bar{D}_{2}\right)}$.

Eq. (51) gives the critical thrust force below which delamination will not occur. Based on the model Eq. (51), the total thrust force is bounded as unit of the sum of $P_{L}$ and $P_{C}$.

According to [5], the minimum critical thrust force corresponds to a value of $=\left(D_{11} / D_{22}\right)^{\frac{1}{4}}$, as shown in Fig. 6. Based on this realization, Eq. (51) becomes:

$$
P_{c}=12 \pi\left(\frac{D_{22}}{D_{11}}\right)^{\frac{1}{4}} \sqrt{\frac{2 G_{c}}{\mathrm{~K}}}
$$

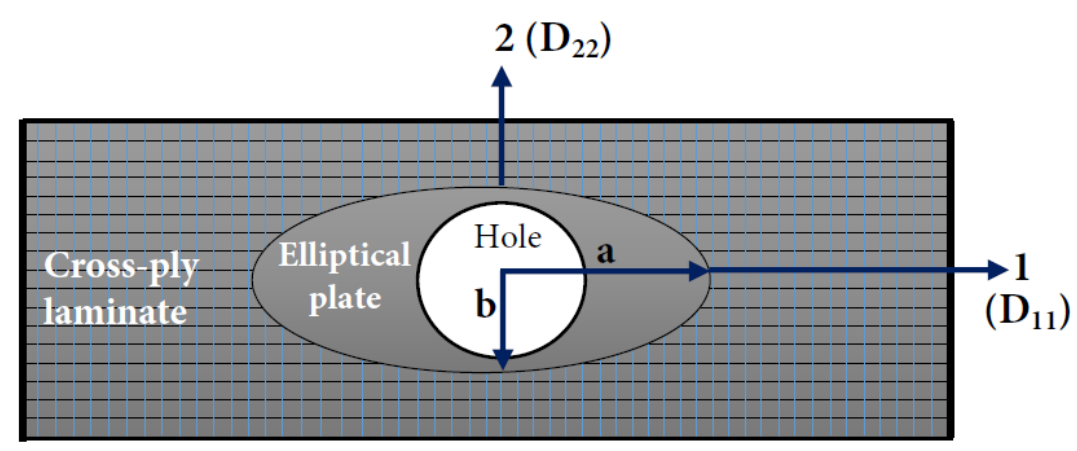

Fig. 6. Delamination zone on a cross-ply laminate modelled as an elliptical plate [53]. 
Table 1. The material properties of the CFRP cross-ply composite laminates [51].

\begin{tabular}{lccccccccc}
\hline Material & $\begin{array}{c}E_{1} \\
(\mathrm{GPa})\end{array}$ & $\begin{array}{c}E_{2} \\
(\mathrm{GPa})\end{array}$ & $\begin{array}{c}v_{12} \\
(\mathrm{GPa})\end{array}$ & $\begin{array}{c}G_{12}=G_{13} \\
(\mathrm{GPa})\end{array}$ & $\begin{array}{c}G_{23} \\
\left(\mathrm{~mJ} / \mathrm{mm}^{2}\right)\end{array}$ & $\begin{array}{c}G_{I I C} \\
\left(\mathrm{~mJ} / \mathrm{mm}^{2}\right)\end{array}$ & $\begin{array}{c}\beta \\
(\mathrm{mm})\end{array}$ \\
\hline CFRP1 & 144 & 8.7 & 0.3 & 4.14 & - & 0.15 & - & - & 0.125 \\
\hline CFRP2 & 138 & 10.5 & 0.3 & 6.3 & 3.5 & 0.98 & 1.625 & 2.3 & 2 \\
\hline
\end{tabular}

\section{Results and discussion}

Materials described in Table 1 are used for the delamination analysis of the laminate during the drilling operation. CFRP1 consists of a 24-ply quasi-isotropic Fibredux 914/T300 (Hexcel) carbon epoxy composite, which has been used for drilling experiment in [61], and used in this paper to analyse the critical thrust force of general composite laminates under distributed load conditions. On the other hand, analysis of critical thrust force for cross-ply laminates is accomplished by using CFRP2, a 24-ply Carbon/PEEK laminate in which the production is described in [59]. The interfacial fracture properties $\left(G_{I C}, G_{I I C}\right.$ and $\left.\beta\right)$ of CFRP2 are determined by conducting pure mode and mixed mode bending (MMB) experiment.

During drilling operation, delamination is assumed to occur when the laminate is drilled so that there are $n$ uncut plies below the drilled hole. The laminate with quasi-isotropic sequence is analysed based on distributed loading assumption and mode I criteria for delamination initiation while the one with cross-ply sequence is assumed to be subjected to mixed loading condition, i.e., part contributions from concentrated and distributed loadings. A mixed mode condition for delamination initiation based on the B-K fracture initiation criterion is specified to calculate the critical thrust force by expressing an effective fracture toughness $G_{c}$ composing of mode I and mode II critical energy release rates. For the quasi-isotropic case, the critical thrust force is computed based on CLPT assumptions for Zhang and Guraja models [4 \& 5] and the critical thrust force is computed for the new model based on assumption of FSDT. For the cross-ply case with mixed loading, the critical thrust force is computed for the model proposed in [53] derived based on CLPT and the new model derived based on FSDT. The relative critical thrust forces for different number of uncut plies are then computed for the two cases considered to demonstrate the effect of shear deformation on the critical thrust force. The effect of chisel edge is also examined for the cross-ply laminate sequence.

The results in Fig. 7 indicate that the proposed FSDT-based and Guraja (CLPT) models gives estimates with minor differences, both showing little discrepancy from the experimental results. Given that the critical thrust force models in [4-5] and the FSDT-based model proposed here are derived based on the assumption of self-similarity of crack propagation, the derived expressions for the critical thrust 
force are independent of the delamination size. Therefore, it is expected that the FSDT-based model derived here produces similar results as the CLPT-based model derived in [5]. This observation can be attributed to the similar estimation of plate deflection produced by FSDT and CLPT subject to high side-to-thickness ratio for thin composite laminates as reported in [44] and since the critical thrust forces described here is not influenced by size of the delamination zone which in turn affects the sideto-thickness ratio of the composite laminate, similar estimations of the critical thrust force by FSDTbased model and CLPT-based model is possible.

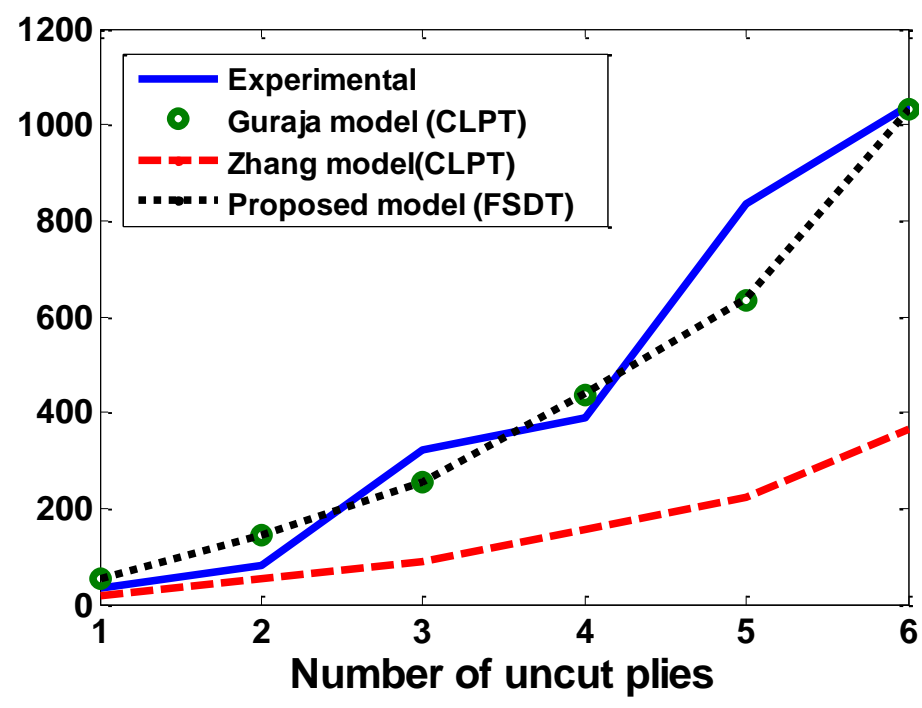

Fig. 7. Critical thrust force based on experimental results and predictions based on proposed FSDT and CLPT-based models [4-5] for quasi-isotropic composite lay-up.

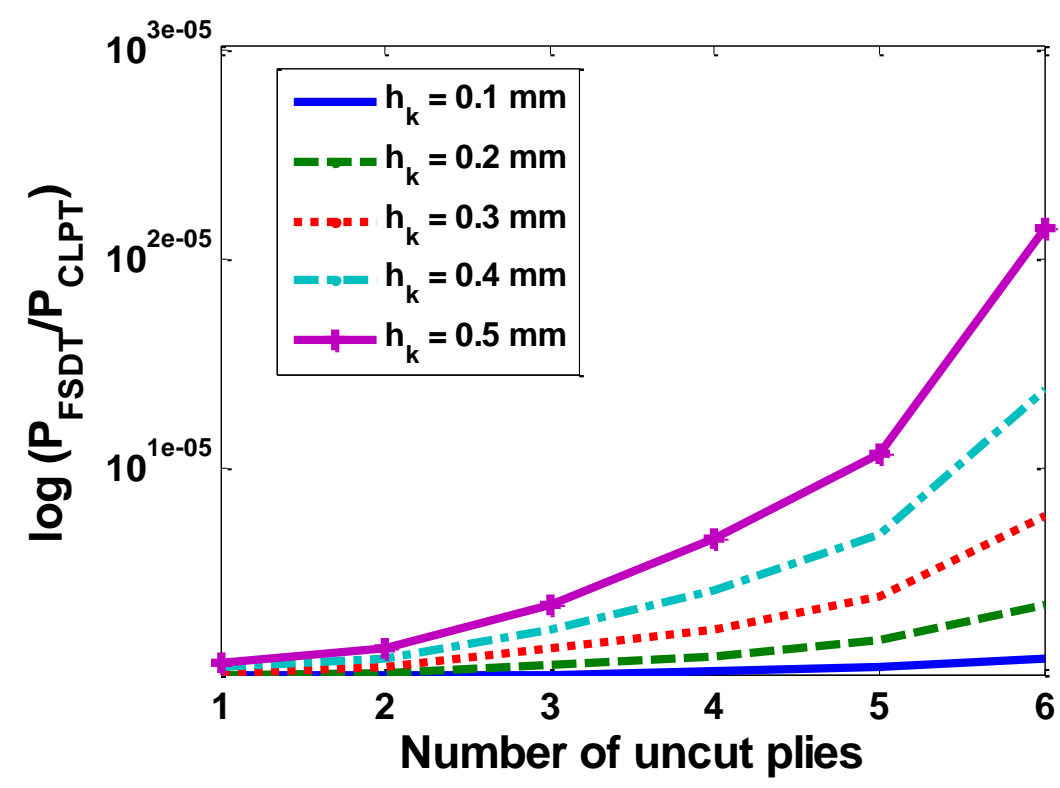

Fig. 8. Critical thrust force difference between first-order shear deformation theory and classical laminate theory for quasi-isotropic composite lay-up with increasing ply thickness. 
To demonstrate the effect of shear deformation on the critical thrust force, ratio of the critical thrust forces estimated by CLPT-based model [5] and the proposed FSDT-based model are computed in Fig. 8 for the CFRP1 composite laminate with different ply thickness $\left(h_{k}\right)$ indicating different side-tothickness ratio. The trend shows increasing effect of shear deformation on the critical thrust forces with increasing ply thickness which is a typical trend for deflection ratio between FSDT and CLPT estimations subject to decreasing side-to-thickness ratio.

The results of relative critical thrust force and critical thrust force difference for the cross-ply configuration using CFRP2 shown in Figs. 9 and 10, indicate similar trends with the quasi-isotropic case. In addition, the effect of chisel edge ratio is observed with initial increase in the relative critical force with increasing chisel edge ratio and a subsequent drop in the magnitude of the critical force at chisel edge ratio greater than 0.4 . This trend is explained by switching of the distributed load controlled process at chisel edge ratio between $0-0.4$ to the concentrated load controlled process at chisel edge ratio greater than 0.4. Essentially, the effect of shear deformation is more significant in the distributed load regime. This is also corroborated by Fig. 11, where it is observed that the relative critical force increases with high slope initially at low chisel edge ratio corresponding to distributed load regime, and tends to a constant value for a high chisel edge ratio corresponding to concentrated load regime. The increasing effect of shear deformation with increasing number of uncut of plies is also corroborated by Fig. 11 as the relative critical force for low number of uncut plies is insignificant with respect to high number of uncut plies.

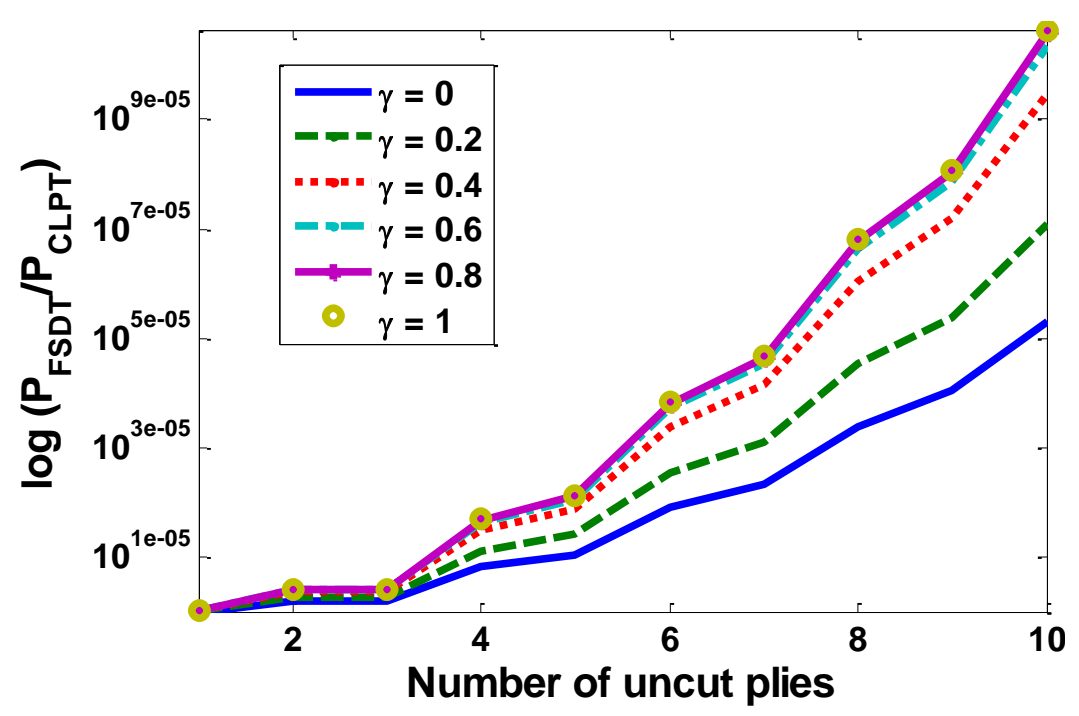

Fig. 9. Relative critical thrust force prediction at different chisel edge ratio for first-order shear deformation theory and classical laminate theory for cross-ply composite lay-up. 


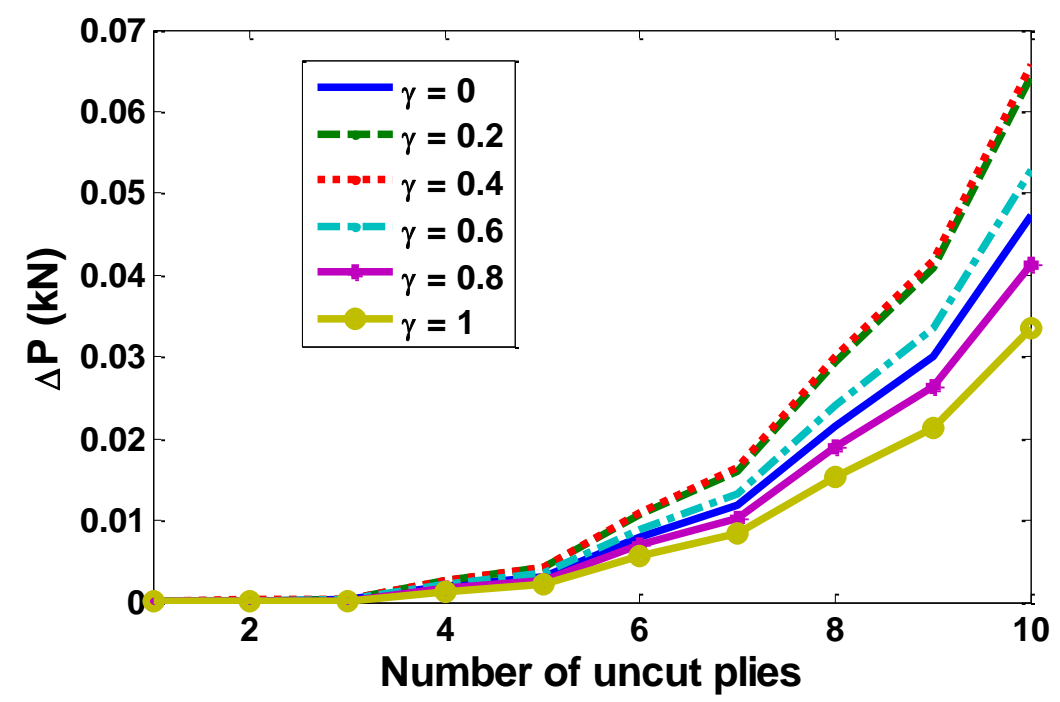

Fig. 10. Critical thrust force difference at different chisel edge ratio between first-order shear deformation theory and classical laminate theory for quasi-isotropic composite lay-up.

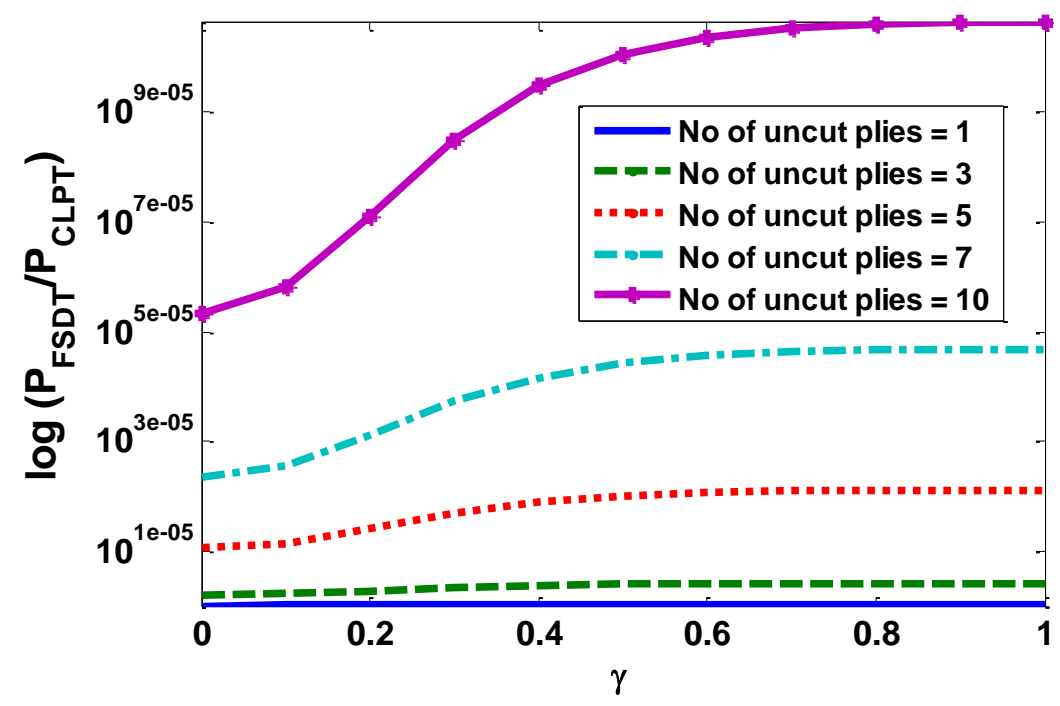

Fig. 11. Effect of chisel edge on relative critical thrust force prediction for first-order shear deformation theory and classical laminate theory for cross-ply composite lay-up.

\section{Conclusions and future development}

A new analytical critical thrust force model for delamination of CFRP laminate during drilling operation has been proposed in this study based on the modified first-order shear deformation theory (FSDT). Unlike previous models in the literature which are derived based on classical laminate plate theory (CLPT) and only account for the mode I strain energy release rate, the present model accounts for mode I and mode II strain energy release rates so that the effect of shear deformation is incorporated in the critical thrust force calculation. To accomplish this task, the transverse displacement is 
partitioned into bending and shear components and the rotational degrees of freedom in the FSDT have been expressed as functions of shear transverse displacement. On this basis, a solution satisfying the condition of elliptic crack configuration has been proposed for the shear transverse displacement.

This development enables the calculation of the critical thrust force for delamination initiation based on mixed mode condition introducing an effective fracture toughness composing of mode I and mode II critical energy release rates as in the B-K fracture initiation criterion. The derivation of the critical force has been partly presented for general laminates subject to distributed load condition and extended to a cross-ply laminate sequence subject to mixed load condition.

The results show that the FSDT-based and CLPT-based models produce estimations with minor difference which is attributed to the self-similarity condition of crack formation assumed in the derivation of the critical thrust force leading to critical thrust force estimations without the influence of delamination size. Effect of shear deformation on the critical thrust force is demonstrated by considering different thickness of the lamina and the results show typical trend reminiscent of deflection ratio estimations by FSDT and CLPT subject to decreasing side-to-thickness ratio. Analysis of cross-ply laminates subject to mixed-load condition indicates that the effect of shear deformation is influential in the distributed load regime.

Since in reality, size of the delamination resulting from the size of the drill affects the initiation and propagation of delamination in the laminate during drilling, a future development will include an extension of the current formulation to reflect the effect of the delamination size on the critical thrust force model which will enable a more adequate evaluation of shear deformation influence on the critical thrust force.

\section{Acknowledgements}

Funding from the European Research Council under the European Union's Seventh Framework Programme (FP/2007-2013)/ERC Grant Agreement No. 306622 (ERC Starting Grant “Multi-field and multi-scale Computational Approach to Design and Durability of PhotoVoltaic Modules" - CA2PVM) is gratefully acknowledged. Similarly, the provision of funding by the Niger-Delta Development Commission (NDDC) of Federal Government, Nigeria, under overseas postgraduate scholarship award number NDDC/DEHSS/2013PGFS/OND/3 is greatly acknowledged. 


\section{REFERENCES}

[1] Chebbi E, Wali M, Dammak F. An anisotropic hyperelastic constitutive model for short glass fibrereinforced polyamide. International Journal of Engineering Science. 106, 2016, 262-272.

[2] Saeed MU, Chen Z, Chen Z, Li B. Compression behavior of laminated composites subjected to damage induced by low velocity impact and drilling. Composites: Part B 56, 2014, 815-820.

[3] Lachaud F, Piquet R, Collombet F, Surcin L. Drilling of composite structures. Composite Structures. 52(3-4), 2001, 511-516.

[4] Zhang LB, Whang LJ, Liu XY. A mechanical model for predicting critical thrust forces in drilling composite laminates. Proceedings of the Institution of Mechanical Engineers, Part B: Journal of Engineering Manufacture, 215(2), 2001, 135-146.

[5] Gururaja S, Ramulu M. Modified exit-ply delamination model for drilling FRPs. Journal of Composite Materials, 43(5), 2009, 483-500.

[6] Tagliaferri V, Caprine G, Diterlizzi A. Effect of drilling parameters on the finish and mechanical properties of GFRP composites. International Journal of Machine Tools and Manufacture, 30(1), 1990, 77-84.

[7] Ismail SO, Dhakal HN, Dimla E, Popov I. Recent advances in twist drill design for composites machining: A critical review. Proceedings of the Institution of Mechanical Engineers, Part B: Journal of Engineering Manufacture, 2016, 1-16.

[8] Isbilir O, Ghassemieh E. Finite element analysis of drilling of titanium alloy. Procedia Engineering, 10, 2001, 1877-1882.

[9] Yang Y, Sun J. Finite element modelling and simulating of drilling of titanium alloy. Proceedings of the Second International Conference on Information and Computing Science, IEEE Computer Society, 2009, 178-181.

[10] Heisel U, Pfeifroth T. Influence of point angle on drill hole quality and machining forces when drilling CFRP. Procedia CIRP, 1, 2012 471-476.

[11] Sambhav K, Tandon P, Dhande SG. Geometric modelling and validation of twist drills with a generic point profile. Applied Mathematical Modelling, 36(6), 2012, 2384-2403.

[12] Paul A, Kapoor SG, DeVor RE. Chisel edge and cutting lip shape optimisation for improved twist drill point design. International Journal of Machine Tools and Manufacture, 45(4-5), 2005 421431.

[13] Ahmadi K, Savilov A. Modeling the mechanics and dynamics of arbitrary edge drills. International Journal of Machine Tools and Manufacture, 89, 2015, 208-220. 
[14] Feito N, Diaz-Álvarez J, López-Puente J, Miguélez MH. Numerical analysis of the influence of tool wear and special cutting geometry when drilling woven CFRPs. Composite Structures, 138, 2016, 285-294.

[15] Arola D, Ramulu M. Orthogonal cutting of fibre-reinforced composites: A finite element analysis. International Journal of Mechanical Science, 39(5), 1997, 597-613.

[16] Campos Rubio JCC , José da Silva L, Leite W, Panzera TH, Filho SLMR , Davim JP. Investigations on the drilling process of unreinforced and reinforced polyamides using Taguchi method. Composites: Part B 55, 2013, 338-344.

[17] Webb PM. Dynamics of the twist drilling process. International Journal of Production Research, 31(4), 1993, 823-828.

[18] Xiong L, Fang N, Shi H. A new methodology for designing a curve-edged twist drill with an arbitrarily given distribution of the cutting angles along the tool cutting edge. International Journal of Machine Tools and Manufacture, 49(7-8), 2009, 667-677.

[19] Jain S, Yang DCH. Effect of feed rate and chisel edge on delamination in composite drilling, Journal of Engineering for Industry, 115(4), 1993, 398-405.

[20] Carrera E. Theories and Finite Elements for Multilayered Anisotropic, Composite Plates and Shells. Arch Comput Methods Eng 2002; 9:87-140.

[21] Reinoso J, Blázquez A. Application and finite element implementation of 7- parameter shell element for geometrically nonlinear analysis of layered CFRP composites. Composite Structures, $139,2016,263-76$.

[22] Karimi NZ, Heidary H, Minak G. Critical thrust and feed prediction models in drilling of composite laminates. Composite Structures, 148, 2016, 19-26.

[23] Saoudi J, Zitoune R, Gururaja S, Mezlini S, Hajjaji AA. Prediction of critical thrust force for exit ply delamination during drill composite laminates: thermo-mechanical analysis. International Journal of Machining and Machinability of Materials, 18(1-2), 2016, 77-98.

[24] Koenig W, Wulf Ch, Grass P, Willerscheid H. Machining of fibre-reinforced plastics. CIRP AnnalsManufacturing Technology, 34(2), 1985, 537-548.

[25] Upadhyay PC, Lyons JS. On the evaluation of critical thrust for delamination-free drilling of composite laminates. Journal of Reinforced Plastics and Composites, 18(14), 1999, 1287-1303.

[26] Timoshenko S, Woinowsky-Krieger S. Theory of Plates and Shells. (2nd Ed.). New York: McGrawHill Book Company, 1959.

[27] Jones RM. Mechanics of Composite Materials. (2nd Ed.). Washington, D.C.: McGraw-Hill Book Company, 1975. 
[28] Bui TQ, Nguyen MN, Zhang C. An efficient mesh free method for vibration analysis of laminated composite plates. Computational Mechanics; 48(2), 2011, 175-93.

[29] Shojaee S, Valizadeh N, Izadpanah E, Bui T, Vu T-V. Free vibration and buckling analysis of laminated composite plates using the NURBS-based isogeometric finite element method. Composite Structures, 94(5), 2012, 1677-93.

[30] Whitney JM, Leissa AW. Analysis of heterogeneous anisotropic plates. J Appl Mech, 36(2), 1969, 261-6.

[31] Ojo SO, Paggi M. Thermo-visco-elastic shear-lag model for the prediction of residual stresses in photovoltaic modules after lamination. Composite Structures, 136, 2016, 481-492.

[32] Ojo SO, Paggi M. A 3D coupled thermo-visco-elastic shear-lag formulation for the prediction of residual stresses in photovoltaic modules after lamination, Composite Structures, 157, 2016, 348-359.

[33] Freddi F, Sacco E. An interface damage model accounting for in--plane effects. Int J Solids Struct $51,2014,4230-4244$.

[34] Paggi $M$, Wriggers $P$. Stiffness and strength of hierarchical polycrystalline materials with imperfect interfaces. J Mech Phys Solids, 60, 2012, 557-572.

[35] Reinoso J, Paggi M, Blázquez A. A nonlinear finite thickness cohesive interface element for modelling delamination in fibre-reinforced composite laminates. Composites: Part B, 109, 2017, 116-128.

[36] Dávila CG, Camanho PP, Turón A. Effective simulation of delamination in aeronautical structures using shells and cohesive elements. Journal of Aircraft, 45 (2), 2008, 663-672.

[37] Paggi M., Reinoso J. An anisotropic large displacement cohesive zone model for fibrillar and crazing interfaces, Int. J. Solids Struct. 69-70, 2015, 106-120.

[38] Qiu Y, Crisfield MA, Alfano G. An interface element formulation for the simulation of delamination with buckling. Eng Frac Mech, 68, 2001, 1755-1776

[39] Reissner E. The effect of transverse shear deformation on the bending of elastic plates. J Appl Mech, 12(2), 1945, 69-72.

[40] Mindlin RD. Influence of rotatory inertia and shear on flexural motions of isotropic, elastic plates. J Appl Mech, 18(1), 1951, 31-8.

[41] Castellazzi G, KrysI P, Bartoli I. A displacement-based finite element formulation for the analysis of laminated composite plates. Composite Structures, 95, 2013, 518-27. 
[42] Cui XY, Liu GR, Li GY. Bending and vibration responses of laminated composite plates using an edge-based smoothing technique. Eng Anal Bound Elem, 35(6), 2011, 818-26.

[43] Thai HT, Choi DH. A simple first-order shear deformation theory for the bending and free vibration analysis of functionally graded plates. Composite Structures, 101, 2013, 332-40.

[44] Thai HT, Choi DH. A simple first-order shear deformation theory for laminated composite plates. Composite Structures, 106, 2013, 754-63.

[45] Bhattacharyya D, Horrigan DPW. A study of hole drilling in kevlar composites. Composites Science and Technology, 58(2), 1998, 267- 283.

[46] Dillio A, Paoletti A, Veniali F. Process in drilling of composites. Proceedings of composite materials symposium, Chicago, Illinois, 1992, 199-203.

[47] Miller JA. Drilling graphite/epoxy at Lockheed. American Machines and Automobiles Manufacture, 131(10), 1987, 70-71.

[48] Chen WC. Some experimental investigation in the drilling of carbon fibre reinforced plastics (CFRP) composite laminates. International Journal of Machine Tools and Manufacture, 37(8), 1997, 1097-1108.

[49] Khashaba UA, El-Sonbaty IA, Selmy Al, Megahed, AA. Machinability analysis in drilling woven GFR/epoxy composites: Part II - Effect of drill wear. Composites Part A: Applied Science and Manufacturing, 41(9), 2010, 1130-1137.

[50] Chandrasekharan VA. A model to predict the three-dimensional cutting force system for drilling with arbitrary point geometry. PhD Thesis, University of Illinois at Urbana-Champaign, United States, 1996.

[51] Chandrasekharan V, Kapoor SG, DeVor RE. A mechanistic approach to predicting the cutting forces in drilling: with application to fibre-reinforced composite materials. Journal of Engineering for Industry, 117(4), 1995, 559-570.

[52] Langella A, Nele L, Maio AA. A torque and thrust prediction model for drilling of composite materials. Composites Part A: Applied Science and Manufacturing, 36(1), 2005, 83-93.

[53] Ismail SO, Ojo SO, Dhakal HN. Thermo-mechanical modelling of FRP cross-ply laminates drilling: Delamination damage analysis, Composites: Part B, 108, 2017, 45-52.

[54] Girot F, Dau F, Gutiérrez-Orrantia ME, New analytical model for delamination of CFRP during drilling, Journal of Materials Processing Technology, 240, 2017, 332-343.

[55] De Zarate Knorr B. Optimisation Du Processus De Perc age d'empilages Hybrides Composites/Titane. Master Thesis. ENSAM, Bordeaux, France, 2014. 
[56] Vlachoutsis S. Shear correction factors for plates and shell, International Journal for Numerical Methods in Engineering, 33, 1992, 1537-1552.

[57] Bui QV. A modified Benzeggagh-Kenane fracture criterion for mixed mode delamination, Journal of Composite Materials, 45(4), 2011, 389-413.

[58] Won MS, Dharan CKH. Chisel edge and pilot hole effects in drilling composite laminates. Journal of Manufacturing Science and Engineering, 124(2), 2002, 242-247.

[59] Naghipour P, Schneider J, Bartsch M, Hausmann J, Voggenreiter H. Fracture simulation of CFRP laminates in mixed mode bending. Engineering Fracture Mechanics, 76(18), 2009, 2821-2833.

[60] Silversides I, Maslouhi A, Laplante G. Interlaminar fracture characterization in composite materials by using acoustic emission. Proceedings of the 5th International Symposium on NDT in Aerospace, Singapore, 2013, 1-10.

[61] Lachuad F, Piquet R, Collombet F, Surcin L. Drilling of Composite Structures. Composite Structures, $52,2001,511-516$.

[62] Grilo TJ, Paulo RMF, Silva CRM, Davim JP. Experimental delamination analyses of CFRPs using different drill geometries. Composites: Part B, 45, 2013, 1344-1350.

[63] Belabed Z, Houari MSA, Tounsi A, Mahmoud SR, Anwar Bég O. An efficient and simple higher order shear and normal deformation theory for functionally graded material (FGM) plates. Composites: Part B, 60, 2014, 274-283.

[64] Singh AP, Sharma M, Singh I. A review of modelling and control during drilling of fibre reinforced plastic composites. Composites: Part B, 47, 2013, 118-25. 